Research Article

Stefan Czypionka* and Frank Kienhöfer

\title{
Weight reduction of a carbon fibre composite wheel
}

https://doi.org/10.1515/secm-2019-0018

Received Jan 28, 2019; accepted Feb 25, 2019

Abstract: The wheel of a passenger vehicle must be designed to be safe and light. Despite the tremendous potential of carbon fibre as an automotive material due to high strength and low weight, the prevalence of carbon fibre reinforced plastics (CFRPs) in vehicle wheels is limited. Manufacturing and testing CFRP prototypes is expensive. Thus it is advantageous to develop simulation models for composite weight reduction. The simulation models can provide insight into how lighter CFRP wheels can be designed. This study presents the design development of a CFRP wheel for a high-performance roadster; the CFRP wheel is offered by an automotive manufacturer as a highperformance option instead of aluminium wheels. Finite element (FE) simulations were initially conducted assuming an isotropic material. This initial model was used to eliminate stress concentrations and to design and manufacture an initial CFRP wheel. The CFRP wheel weight is $6.8 \mathrm{~kg}$ as compared to the original aluminium wheel which weighs $8.1 \mathrm{~kg}$. This initial design passed the dynamic cornering fatigue test (the most stringent strength test for wheels). Thereafter the wheel was instrumented with strain gauges and a bending moment was applied to the hub using a custom-built test rig. The test rig produced a static load equivalent to the dynamic cornering fatigue test (in which the applied bending moment varies sinusoidally). The test rig allowed for the deflection of the load arm to be measured. The comparison of the experimentally measured strains and an FE model which includes the CFRP laminate properties showed good agreement. Two alternative laminate options were simulated using the FE model. These showed both an increase in stiffness and a calculated weight reduction. This study shows that an aluminium wheel for a high-performance roadster can be redesigned using CFRP to be $16 \%$ lighter and using a FE

\footnotetext{
*Corresponding Author: Stefan Czypionka: University of the Witwatersrand, 1 Jan Smuts Avenue, Braamfontein, Johannesburg, South Africa; Email: stefan.czypionka@students.wits.ac.za Frank Kienhöfer: University of the Witwatersrand, 1 Jan Smuts Avenue, Braamfontein, Johannesburg, South Africa
}

model a further $152 \mathrm{~g}$ weight reduction is possible $(18 \%$ weight reduction in total when compared to the aluminium wheel).

Keywords: Carbon fibre; composite wheels; finite element analysis, bending stiffness

\section{Introduction}

\subsection{Background}

The wheel is arguably one of the most important components of a road going vehicle. It is responsible for the transmission of power from the drive components of the vehicle to the road, while also enabling the vehicle to make directional changes. Overdesigning a wheel by adding material increases the wheel mass and rotational inertia which negatively affects the vehicle's performance and efficiency. This has led to substantial development efforts to reduce the wheel weight and rotational inertia while simultaneously maintaining or increasing the material strength [1]. A wheel must be designed to be safe and light.

Numerous research studies have been published on the development of steel [2-4] and aluminium [5-10] wheels. Steel and aluminium alloy wheels have arguably reached the peak of possible weight reduction and composite materials offer the next advance. Despite the tremendous potential of carbon fibre as an automotive material due to high strength, low density and superior fatigue properties, the prevalence of carbon fibre reinforced plastics (CFRPs) wheels and corresponding published research is limited. Giger and Ermanni [11] demonstrated the development process of a CFRP motorcycle rim. However, this wheel was not tested to certified standards. Rondina et al. [12] investigated a high volume production method for carbon fibre wheels. The paper simulated the production process; however, no certified wheel appears to have been produced. As early as 1979, studies have been conducted into the viability of composites for use as automotive wheels $[13,14]$.

Unlike isotropic materials, CFRP components are expensive to test and certify. Even small changes in geome-

ə Open Access. () 2019 S. Czypionka and F. Kienhöfer, published by De Gruyter. 
try to prevent failure or reduce stresses could cause a production line to be re-tooled during the development process and existing equipment to be scrapped. This research paper illustrates the development of a validated finite element (FE) model to investigate laminate configurations to improve the stiffness of the CFRP wheel and be $18 \%$ lighter than the original aluminium wheel. The case study is of an original equipment (OE) wheel designed and manufactured by Blackstone Tek (BST) [15].

\subsection{Literature Review}

The following section discusses the importance of reducing weight in the wheel and details the mechanical testing that is required to certify wheels.

\subsubsection{The importance of reducing wheel weight}

A rotating element, such as a wheel, has two inertial components: its mass $(\mathrm{m})$ and its rotational inertia $(I)$. Forward vehicle motion requires fuel to be expended to give the wheel translational as well as rotational energy. The wheel thus has an increased effective mass $\left(m_{e}\right)$, where the effective mass is described by the mass of the wheel $(m)$, its rotational inertia $(I)$ and the ratio between its rotational speed and linear velocity $(n)$ [16]:

$$
m_{e}=m+I n^{2}
$$

The fuel saving benefit of reducing wheel weight is thus amplified when compared to the weight saving of nonrotational components.

\subsubsection{Wheel Development and Testing}

Giger and Ermanni [11] developed a CFRP motorcycle rim using computer simulation. The work highlighted that the number of variables involved with the optimisation of CFRP components is high. An evolutionary algorithm was developed to determine the optimal parameters for the manufacture of the wheel. The variations of prepreg materials with different fibre layouts, the number of fibre plies and the orientation of each ply were optimised [11]. The simulated tests were developed from first principles and considered the forces acting during maximum braking and lateral loading of the wheel. While the work showed the method that was employed, the calculated optimal parameters were not published. Furthermore, the simulated tests were not as per certified ISO or SAE standards.
To certify the structural integrity of wheels before they are introduced to market, several fatigue tests to simulate strenuous road conditions are carried out [17]. Tests are carried out to simulate three basic driving conditions, radial fatigue for straight driving, cornering fatigue for repeated bending moments and impact testing to simulate curb strikes and potholes.

FE models are used to reduce the number of prototypes required for testing. Testing without the use of FE models will not provide optimal results [5]. In addition, the complex shapes that are common in styled wheels all but exclude the use of analytical methods [7]. FE simulations have been conducted on wheels under radial loads [7-9, 18], bending loads [2-4, 6, 10] and impact conditions [19].

The most strenuous wheel test is the dynamic cornering fatigue test (DCF) $[2,4,6]$. If a wheel passes this fatigue test it has a high likelihood of passing all other strength tests. Dynamic cornering fatigue tests are generally conducted in accordance with the method described in ISO 3006. While testing standards have evolved over time to certify new materials such as lightweight steels and aluminium [17], no certified test existed for CFRP wheels at the start of this study. A testing standard developed by the TÜV in conjunction with major manufacturers of composite wheels existed only in draft form. The standard has since been published [20].

Figure 1 illustrates the rig that is used to conduct the dynamic cornering fatigue test. The test is conducted by clamping a wheel to a stationary table top or platform and subjecting it to a bending moment by means of a rotat-

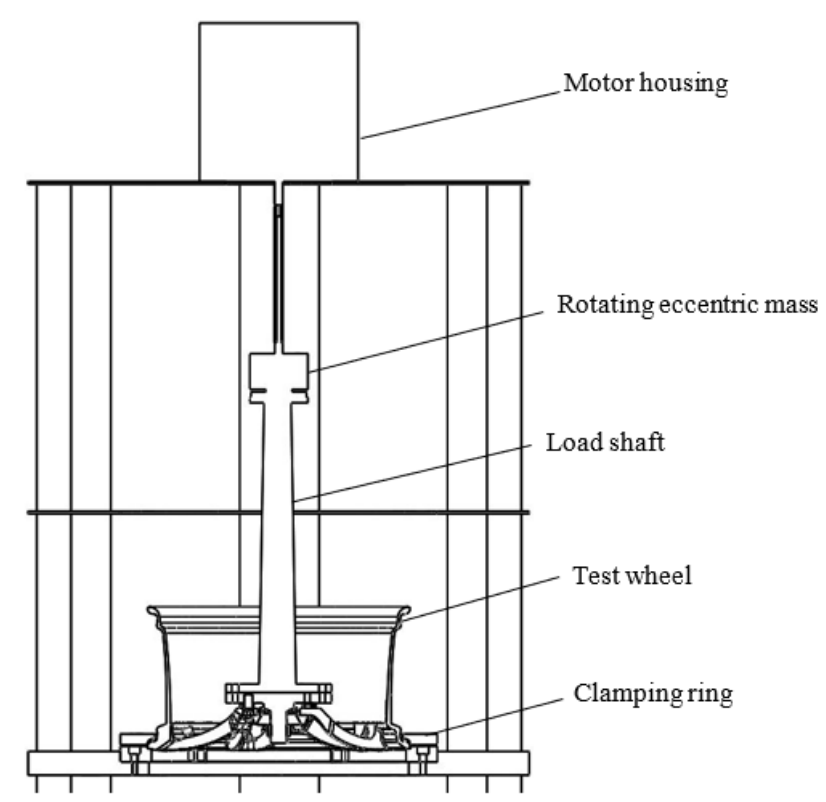

Figure 1: Schematic of the dynamic cornering fatigue test rig 

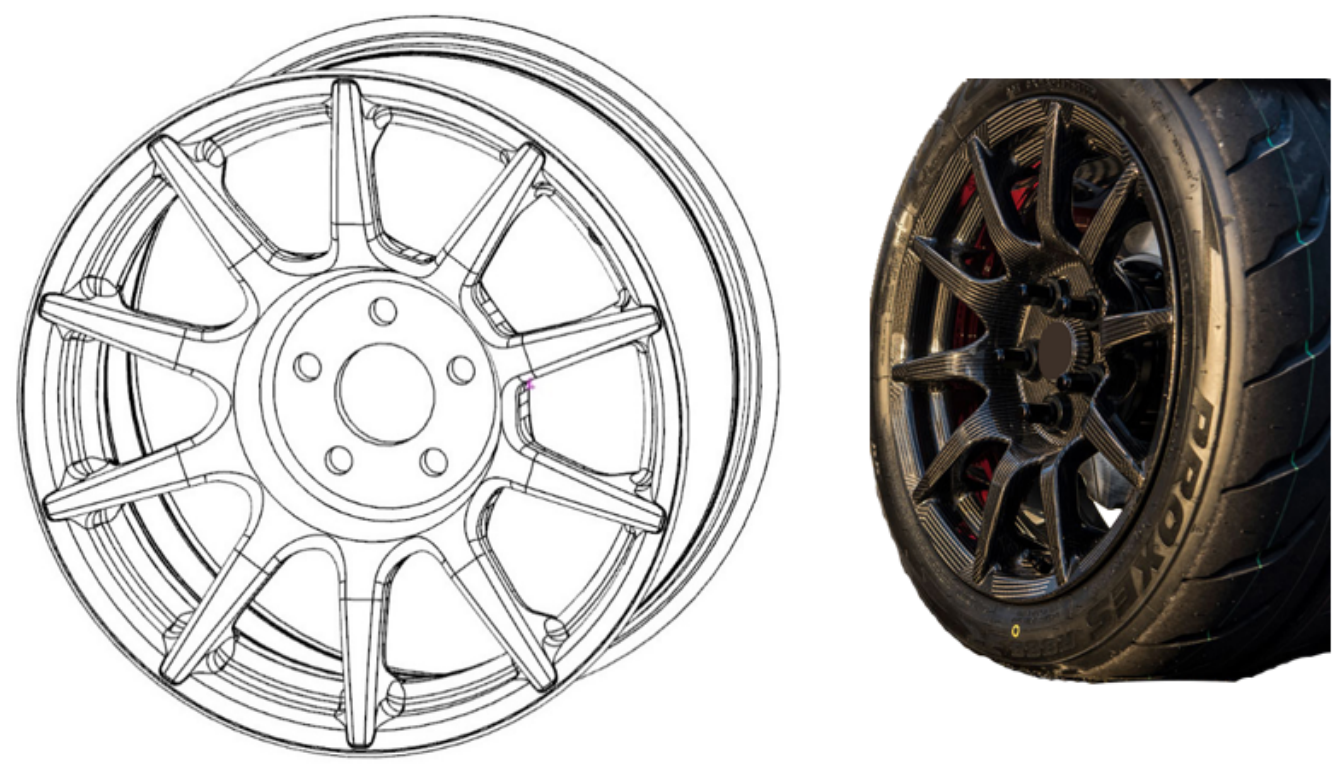

Figure 2: (a) Computer model of the tested wheel; (b) Manufactured BST wheel fitted to a tyre

ing eccentric mass located at the end of a loading arm, attached to the wheel hub.

\subsection{Objective}

The main objective of this study was to validate a finite element (FE) model of a CFRP wheel. The validated model was used to theoretically reduce the weight of the wheel while increasing the bending stiffness of the wheel.

\section{Experimental testing and simulation}

This section describes the wheel specifications, the experimental setup and procedure to validate the composite FE model of the wheel and the setup of the composite FE model.

\subsection{Tested prototype and instrumentation}

The test sample was a new design developed for an OE vehicle manufacturer by BST and measures 9 inches wide by 18 inches in diameter (9Jx18). Figure 2a shows the CAD model and Figure $2 \mathrm{~b}$ shows the manufactured wheel. The laminate consisted of pre-impregnated (prepreg) carbon fabrics. The fabrics were impregnated with an epoxy resin. The pre-preg material was cut in shapes (plies) to fit the pre-selected surfaces of the mould. The laminate was constructed using two plain woven pre-preg fabrics and one unidirectional (UD) pre-preg fabric. The first woven material was selected as a cosmetic layer. The cosmetic material is lighter but significantly more expensive than the other woven or UD laminate. Thereafter the non-cosmetic woven and UD laminates were alternated. The UD material was orientated with the fibres in line with spoke, and the woven material was orientated with the fibres at $45^{\circ}$ to the spoke. Each additional layer improves the strength and stiffness of the spoke but at the expense of additional mass.

FE simulations were initially conducted assuming an isotropic material. Strictly speaking the stress concentrations of an isotropic material are only dependent on the geometry; while for an orthotropic material the stress concentrations are also dependent on the elastic properties of the material. Nevertheless, the use of an approximate isotropic FEA model (which is quick to construct compared to an FEA model which includes the laminate details) is extremely useful to eliminate stress concentrations by reducing the curvature at the points where stress concentrations occur and to identify locations of high stress where an increased number of plies are required. This initial geometry was used to manufacture a CFRP wheel with a weight of $6.8 \mathrm{~kg}$ as compared to the original aluminium wheel used by the OE manufacturer which weighs $8.1 \mathrm{~kg}$. This initial design passed the dynamic cornering fatigue test. This prototype was used to validate a composite FE model of the wheel. 
Table 1: Instrumentation used on the experimental prototype

\begin{tabular}{llc}
\hline Item & Name & Quantity \\
\hline Strain gauge & $\begin{array}{l}\text { Kyowa KFRP-5-350- } \\
\text { C1-1 }\end{array}$ & 4 \\
Cable & $\begin{array}{l}\text { Twisted three core } \\
\text { shielded cable }\end{array}$ & 4 \\
Chassis & $\begin{array}{l}\text { National Instru- } \\
\text { ments SCXI-1000 }\end{array}$ & 1 \\
Strain gauge card & $\begin{array}{l}\text { National Instru- } \\
\text { ments SCXI-1520 }\end{array}$ & 1 \\
Terminal block & $\begin{array}{l}\text { National Instru- } \\
\text { ments SCXI-1314 }\end{array}$ & 1 \\
Data acquisition con- & $\begin{array}{l}\text { National Instru- } \\
\text { ments SCXI-1600 } \\
\text { troller } \\
\text { Computer software }\end{array}$ & 1 \\
\hline
\end{tabular}

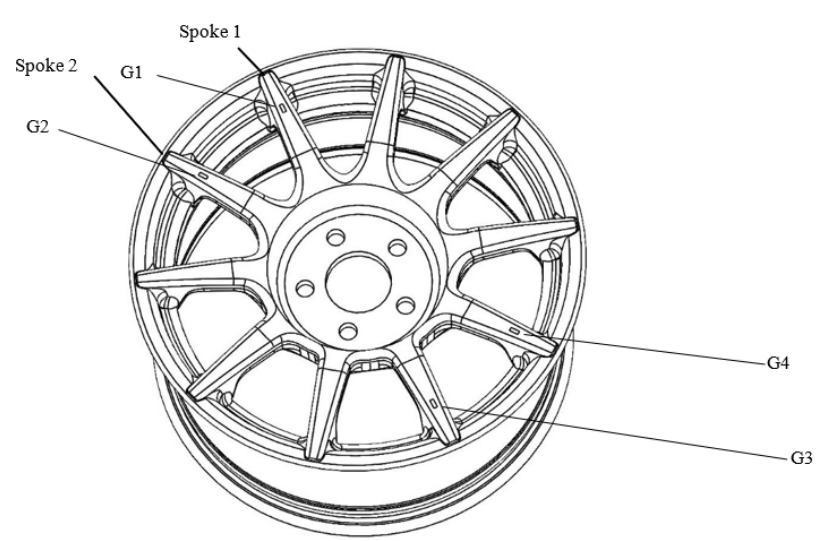

Figure 3: Placement of strain gauges on the experimental prototype

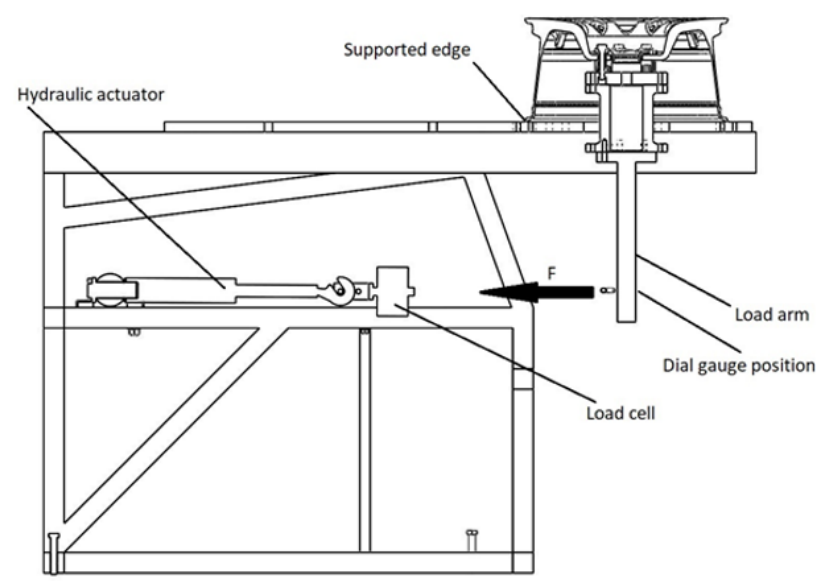

Figure 4: Cross-sectional schematic of the apparatus used

The experimental prototype was instrumented with 4 Kyowa KFRP-5-350-C1-1 strain gauges that were placed on the outer surface of the wheel on the spokes. Figure 3
Table 2: Technical specifications of the strain gauges

\begin{tabular}{cc}
\hline Item & Details \\
\hline Gauge factor & $2.02 \pm 1.5 \%$ \\
Gauge resistance & $350 \Omega \pm 1.2 \Omega$ \\
\hline
\end{tabular}

shows the positions of the strain gauges on the wheel. Strain gauge 1 (G1) was positioned on a spoke in line with a bolt-hole, labelled spoke 1 . Strain gauge 2 (G2) was placed on an adjacent spoke labelled spoke 2 which was counter clockwise to spoke 1 . Strain gauge 3 (G3) was placed opposite of strain gauge 1 , while strain gauge 4 (G4) was placed opposite of strain gauge 2 . The strain gauges were connected to a National Instruments data acquisition system (see Table 1). While precautions were taken to align the gauges along marked lines, misalignment of the gauges was observed after the adhesive had cured. The observed direction of the misalignment of the strain gauges (i.e. angled away or from the centre or direction of the loading) was noted.

Table 2 lists the technical information of the strain gauges used. The sampling rate was set at $1000 \mathrm{~Hz}$, the cut-off frequency of the low-pass filter at $100 \mathrm{~Hz}$, and the strains for a given applied load were recorded over a period of 3 seconds and averaged to reduce the error caused by noise.

\subsection{Experimental apparatus and methodology}

Figure 4 shows the setup of the experimental apparatus used to test the wheel. The bending moment at the mounting face of the wheel was applied using a load arm and hydraulic actuator. The test rig applied a bending moment in one direction only which modelled an equivalent static load case of an instant in time of the DCF test. The wheel movement in the DCF test is small and thus the corresponding inertial forces are insignificant (justifying the use of an equivalent static load approximation). This has been confirmed with FEA simulations comparing the static loading stresses to a full dynamic case. Previous research $[2,3]$ has used FEA of the equivalent static loading case to model the DCF test.

The testing equipment used pre-existing load arms and spacers, and thus the direction of the force applied was limited to bolt-hole configurations that placed the load arm hook towards the cylinder. The direction of the load application was between 2 instrumented spokes. It was expected to obtain similar readings between gauges $\mathrm{G} 1$ and 
G2; as well as G3 and G4. However, notably different strains in gauges between G1 and G2; as well G3 and G4 were observed. As stated in Section 2.1, the strain gauges were observed to have slight misalignment from the centreline of the spoke. It was noted that the gauges that were misaligned at an angle closer to that of the applied load had a higher measured strain. The opposite was observed when gauges were misaligned away from the applied load. Gauge G3 was observed to be well aligned and in good agreement with the FE model.

The applied load was measured in kgf using a load cell. The actuator and load cell were connected to the load arm by means of a chain. As the chain and load cell, have a mass which must be accounted for, the actuator was retracted until the slack in the chain was removed. The load cell was set to zero from this point and all loads were measured from the established "slack" datum.

In addition to the strain gauges and load cell, a dial gauge was placed at the end of the loading arm to measure the deflection at the end of the loading arm as the load was applied. The dial gauge was fixed to the steel frame by means of a magnetic foot. The dial gauge measured the deflection of the load arm and has a quoted accuracy of $\pm 0.005 \mathrm{~mm}$.

Two experimental tests (test 1 and test 2 ) were run. Test 2 was a repeated test, where the wheel was removed from the rig, repositioned, clamped and tested again.

\subsection{Finite element model}

The initial approximate isotropic FE model used to determine stress concentrations was insufficiently detailed to optimise the weight. The material properties, ply thickness, and fibre orientation of each ply or lamina of each laminate of the wheel needed to be specified. This was achieved using ANSYS ACP (ANSYS Composite PrepPost). A surface model was generated (See Figure 5) and exported as a Parasolid into ANSYS workbench to create the composite FE model. With the geometry of the simulation imported, the material properties of each laminae were defined. The pre-defined ANSYS materials Epoxy Carbon UD (230 GPa) Prepreg and Epoxy Carbon Woven (230 GPa) Prepreg were selected to define fabrics as a first approximation.

To define a fabric in the Engineering Data section of a workbench project requires the definition of the orthotropic elasticity, orthotropic stress limits and orthotropic strain limits of the laminae (individual sheets). The stress and strain limits are important when attempting to predict failure of the model. The orthotropic elas-

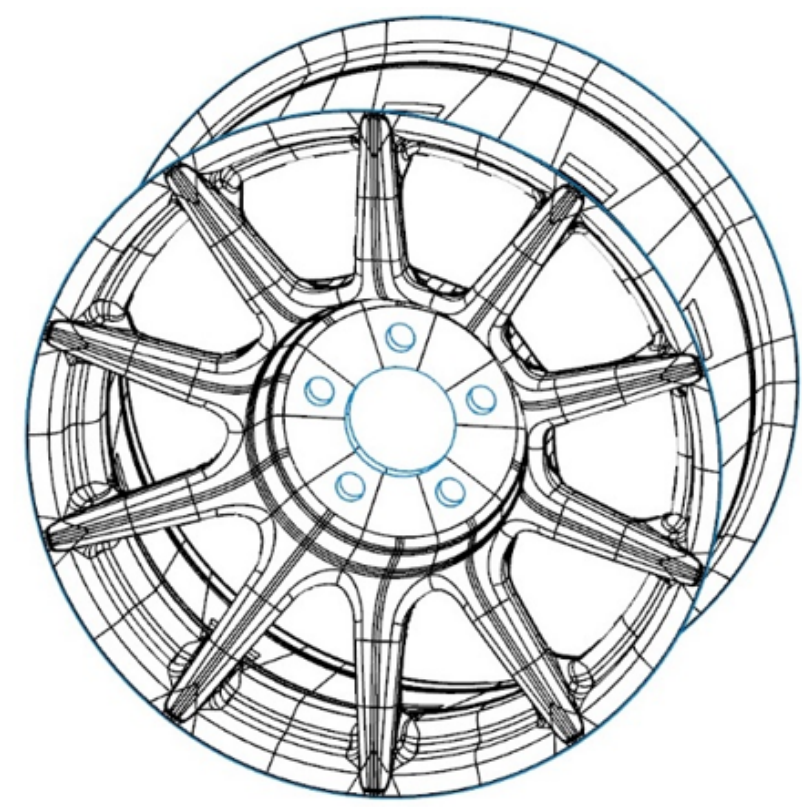

Figure 5: Surface model used for composite FE analysis

ticity is required to determine the mechanical response of the geometry to applied loading conditions. Orthotropic elasticity is defined by the Young's Modulus in the axial directions $\left(E_{x}, E_{y}, E_{z}\right)$, the Poisson's Ratio in the directional planes $\left(v_{x y}, v_{y z}, v_{x z}\right)$ and the shear modulus in the directional planes $\left(G_{x y}, G_{y z}, G_{x z}\right)$. Tensile testing was later conducted on material samples. The obtained directional stiffness values $\left(E_{x}\right.$ and $\left.E_{y}\right)$ were compared to the ANSYS database. The material definition was updated accordingly. The fibre reference directions were defined using rosettes placed strategically around the surface model that utilised the named edges in what is termed an Oriented Selection Set (OSS). The OSS combines the named selections of surfaces for each ply, the rosettes and an individually selected surface normal to generate each type of ply. Care was taken to define the fibre reference direction of each lamina accounting for the draping of the material over complex geometry. Figure 6(a) shows the default fibre reference direction generated by ACP; which does not accurately represent the true fibre direction. Figure 6(b) shows the fibre reference direction after the draping function is utilised. While this is not a true representation of the fibre direction, it serves as a close approximation.

The ACP (pre) cell model was exported using shell elements to the ANSYS static modelling environment. Tetrahedral elements with mid-side nodes were used to generate the mesh. The mesh contained 174028 surface elements and had an average quality of 0.827 . A second mesh with quadrilateral elements was attempted, but ANSYS was unable to generate the mesh on all surfaces. Gener- 


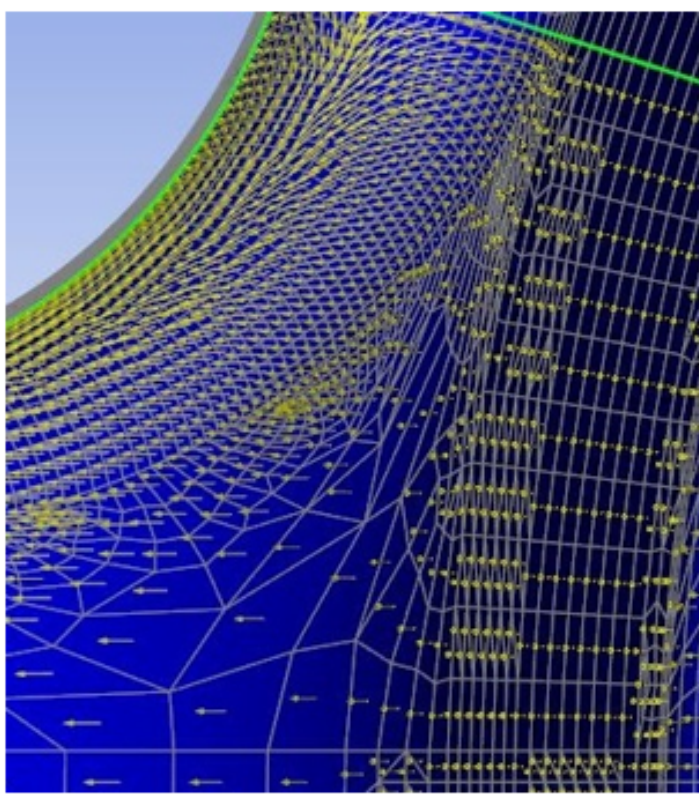

(a)

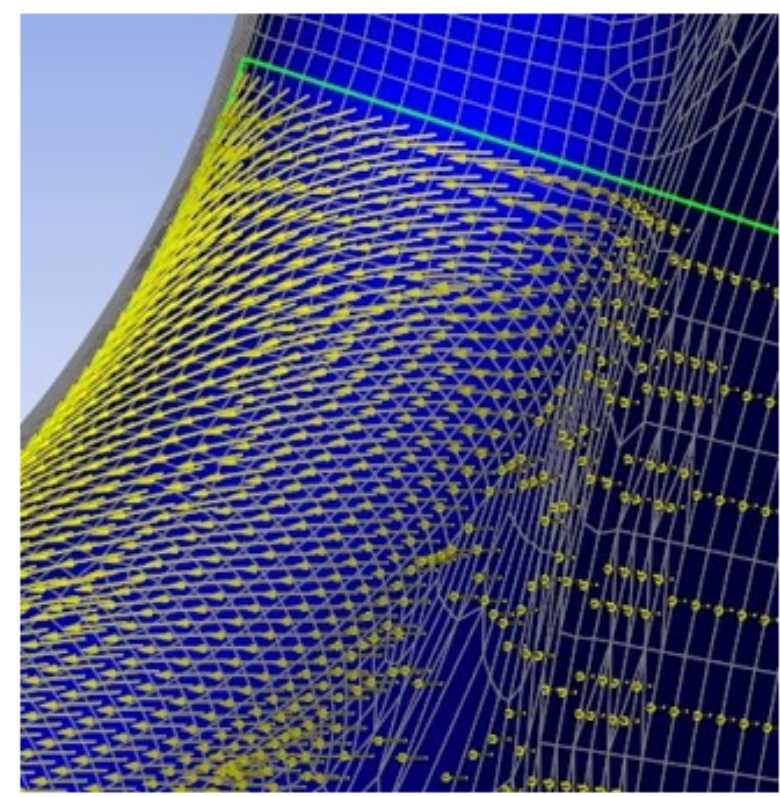

(b)

Figure 6: (a) Fibre reference direction of a ply before draping; (b) fibre reference direction after draping

ating a solid model was not possible due to the complex 3D geometry and the large number of elements and nodes that would have been too large for the available computing power to handle. The geometry was modelled as a surface body. The load was simulated using a remote force that was applied to the hub area of the wheel with an effective distance matching the load arm in the physical test. The wheel was constrained using fixed supports on the supported edge shown in Figure 4. Strain probes were placed on the wheel at the locations of the strain gauges shown in Figure 3.

\section{Experimental results and discussion}

Figure 7 shows the measured strains of gauges G1 to G4 versus an increase in applied load on the bending stiffness apparatus, as well as the corresponding FE results for the gauge positions. Uncertainty in the measurement was determined from the propagation of error considering the manufacturer specified variance in gauge factor and gauge resistance. The calculated error was insignificant and not included in the figure. The differences in measured strain of $\pm 2 \mu \epsilon$ between incremental loading and unloading indicate a small amount of hysteresis present in all measurements. The experimentally measured strain values and those determined from the FE model increase linearly as expected. The orientation of the gauges G1, G2, and $\mathrm{G} 4$ in the FE model were adjusted $\left(<5^{\circ}\right)$ to compensate for the misalignment when gluing the gauges on the complex geometry of the wheel. The gauge $\mathrm{G} 3$ was well-aligned. The simulated strains show good agreement with the measured values.

Figure 8 shows the deflection of the load arm during the experimental tests. The deflections are linearly related to the loading as expected. The difference in measured deflection of approximately $0.3 \mathrm{~mm}$ between loading and unloading and the deflection not returning to zero at the end of the test, indicate a small amount of hysteresis present. The measured values of deflection are in close agreement between test 1 and test 2, indicating the experiment is repeatable.

For the purpose of this study the model was assumed to have been validated. The composite FE model was used to evaluate two alternative laminate configurations for further weight reduction. Figure 9 shows the simulated strain values used to evaluate the stiffness of the concept configurations. A reduction in measured strain values correlates with a reduction in deflection, and thus an increase in stiffness. The concept laminates are termed concept 1 and concept 2 . Stiffness was chosen as a property to compare the laminates as this was used in experimentation. Stiffness gives an indication of strength in the DCF test. A reduction in stiffness during the test is used to terminate the DCF test. 


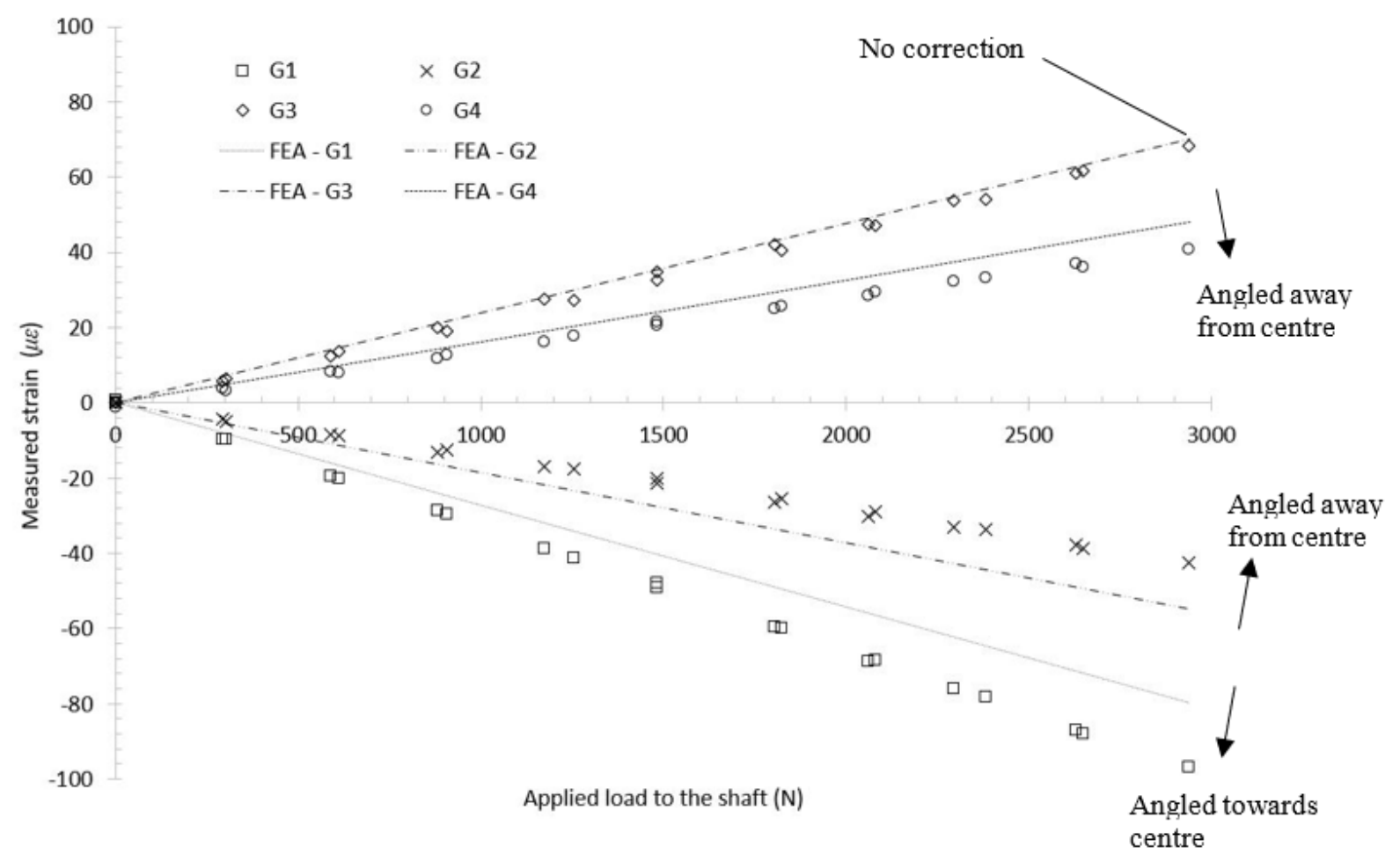

Figure 7: Measured strains on the spokes with FE results

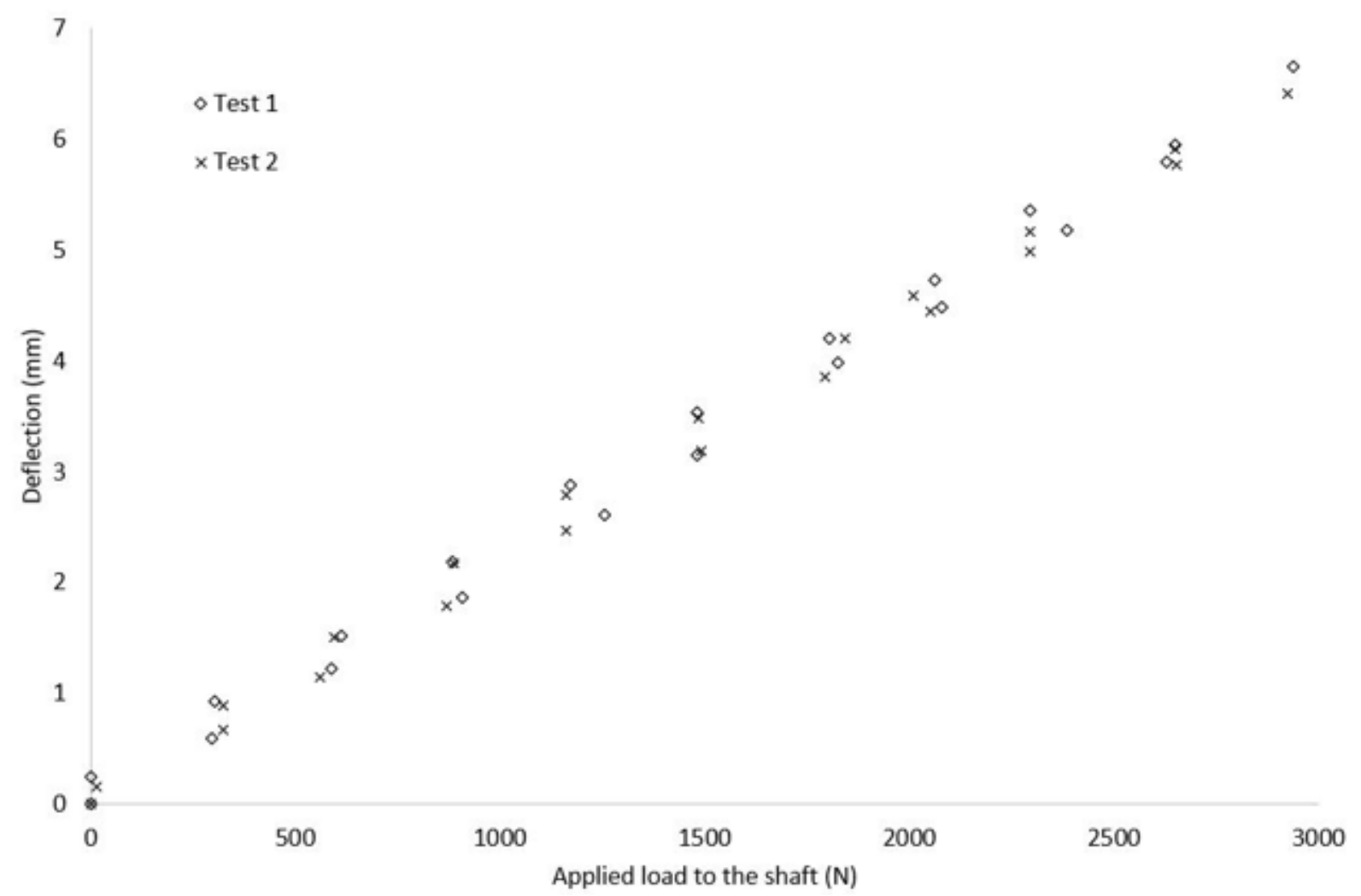

Figure 8: Experimental deflection of the load arm for test 1 and 2 


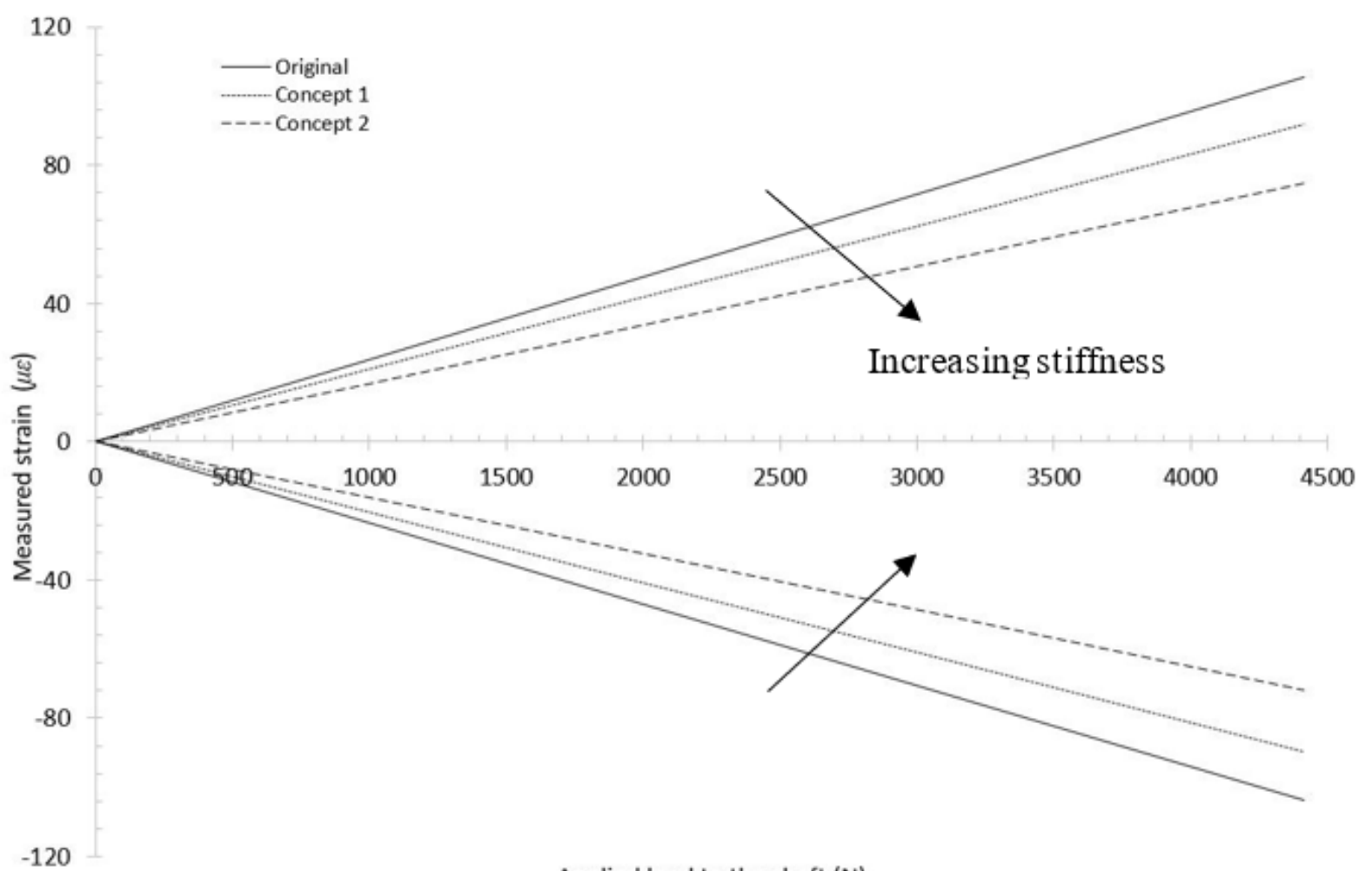

Applied load to the shaft (N)

Figure 9: Simulated strain values for alternative laminate configurations

The change proposed for concept 1 was the removal of a single layer of plain woven prepreg from the entire geometry and placing new UD plies in the spoke of the wheel. The change proposed for concept 2 was the complete replacement of the plain woven prepreg with the cosmetic woven prepreg in the entire laminate, while further adding UD plies in each UD layer. The mass reduction of the concept configurations was estimated by using the surface area of each placed ply and the areal mass (in $\mathrm{g}$ per $\mathrm{m}^{2}$ ) of the material types. This resulted in an estimated weight saving of $134 \mathrm{~g}$ for concept 1 and $152 \mathrm{~g}$ for concept 2 . The complex setup of the composite FE model limits the number of concept configurations that can be run without having to rebuild the laminate.

The concept laminates were not chosen to be used in the production wheel, rather they show that the composite FE model has the potential to be used for experimenting with laminate configurations.

\section{Conclusions}

The study presented the development and validation of a composite FE model to optimise a lightweight 9Jx18 car- bon fibre wheel for a passenger vehicle. Finite element (FE) simulations were initially conducted assuming an isotropic material. This initial model was used to eliminate stress concentrations and design and manufacture an initial CFRP wheel. The CFRP wheel weight is $6.8 \mathrm{~kg}$ as compared to the original aluminium wheel which weighs $8.1 \mathrm{~kg}$. This initial design passed the dynamic cornering fatigue test. The strains on the spoke of a prototype CFRP wheel were measured on a custom-built test rig which applies the equivalent static load of the dynamic cornering fatigue test rig; i.e. the bending moment is applied in one direction only and does not rotate. The experimentally measured strains increased linearly with increasing load as expected. The measurements have acceptable test-retest variability. These strains were used to validate an FE model of the CFRP wheel (including the layup details). Two alternative laminates were evaluated to further reduce weight, while increasing the bending stiffness. The composite FE model illustrated that a further $152 \mathrm{~g}$ weight reduction is possible which corresponds to an $18 \%$ weight reduction in total when compared to the aluminium wheel.

Acknowledgement: This work was conducted in cooperation with an industry partner, Blackstone TEK (BST) 
[15]. The authors would like to thank merSETA for financially supporting MSc student Stefan Czypionka.

\section{References}

[1] F. Fitz and C. Gadd, "Development of a Light Weight Passenger Car Wheel Using Conventional Steels and Fabrication Techniques," SAE Tech. Pap. Ser., vol. 01, no. 0782, 1999.

[2] X. Wang and X. Zhang, "Simulation of dynamic cornering fatigue test of a steel passenger car wheel," Int. J. Fatigue, vol. 32, no. 2, pp. 434-442, 2010.

[3] Z. G. Zheng, T. Sun, X. Y. Xu, S. Q. Pan, and S. Yuan, "Numerical simulation of steel wheel dynamic cornering fatigue test," Eng. Fail. Anal., vol. 39, pp. 124-134, 2014.

[4] U. Kocabicak and M. Firat, "Numerical analysis of wheel cornering fatigue tests,” Eng. Fail. Anal., vol. 8, no. 4, pp. 339-354, 2001.

[5] R. Muthuraj, R. Badrinarayanan, and T. Sundararajan, "Improvement In The Wheel Design Using Realistic Loading Conditions FEA and Experimental Stress Comparison," SAE Int., vol. 28, no. 0106, 2011.

[6] Y.-L. Hsu and M.-S. Hsu, "Weight reduction of aluminum disc wheels under fatigue constraints using a sequential neural network approximation method," Comput. Ind., vol. 46, no. 2, pp. 167-179, 2001.

[7] P. R. Raju, B. Satyanarayana, K. Ramji, and K. S. Babu, "Evaluation of fatigue life of aluminum alloy wheels under radial loads," Eng. Fail. Anal., vol. 14, no. 5, pp. 791-800, 2007.

[8] J. Stearns, T. S. Srivatsan, A. Prakash, and P. C. Lam, "Modeling the mechanical response of an aluminum alloy automotive rim," Mater. Sci. Eng. A, vol. 366, no. 2, pp. 262-268, 2004.

[9] M. Firat, R. Kozan, M. Ozsoy, and O. H. Mete, "Numerical modeling and simulation of wheel radial fatigue tests," Eng. Fail. Anal., vol. 16, no. 5, pp. 1533-1541, 2009.
[10] P. Li, D. M. Maijer, T. C. Lindley, and P. D. Lee, “A through process model of the impact of in-service loading, residual stress, and microstructure on the final fatigue life of an A356 automotive wheel," Mater. Sci. Eng. A, vol. 460-461, pp. 20-30, 2007.

[11] M. Giger and P. Ermanni, "Development of CFRP racing motorcycle rims using a heuristic evolutionary algorithm approach," Struct. Multidiscip. Optim., vol. 30, no. 1, pp. 54-65, 2005.

[12] F. Rondina et al., "Development of full carbon wheels for sport cars with high-volume technology," Compos. Struct., vol. 192, no. January, pp. 368-378, 2018.

[13] R. A. Ridha, "Fiber-Reinforced Automotive Wheels-Promises and Challenges," in SAE Technical Paper, 1979.

[14] A. J. Wootton, J. C. Hendry, A. K. Cruden, and J. D. A. Hughes, "Structural Automotive Components in Fibre Reinforced Plastics," in Composite Structures 3, I. H. Marshall, Ed. Dordrecht: Springer Netherlands, 1985, pp. 19-42.

[15] Blackstone TEK, "BST Carbon Fiber Car Wheels," 2017. [Online]. Available: http://blackstonetek.com/bst-best-carbon-fiberwheels-home/bst-carbon-fiber-car-wheels/.

[16] D. Hrovat, "Influence of unsprung weight on vehicle ride quality," J. Sound Vib., vol. 124, no. 3, pp. 497-516, 1988.

[17] J. Kinstler, "The Science and Methodology of SAE Wheel Fatigue Test Specifications," SAE Tech. Pap. Ser., vol. 01, no. 1826, 2005.

[18] C. P. De Carvalho, H. Jacobus, C. Voorwald, and C. E. Lopes, "Automotive Wheels - An Approach for Structural Analysis and Fatigue Life Prediction," Sae Pap. 2001-01-4053, no. September 2015, pp. 237-243, 2001.

[19] M. B. K, S. Vinothkumar, S. Srinivasan, and A. Nesarikar, "Simulation and Test Correlation of Wheel Impact Test," SAE Tech. Pap. Ser., vol. 28, no. 0129, 2011.

[20] TUV, "Guidelines for the testing and inspection of plastic wheels for passenger cars and motorcycles, as at 17 January 2019," no. January, pp. 1-14, 2019. 